\title{
Nanodiamond Batch Enriched with Boron: Properties and Prospects for Use in Agriculture
}

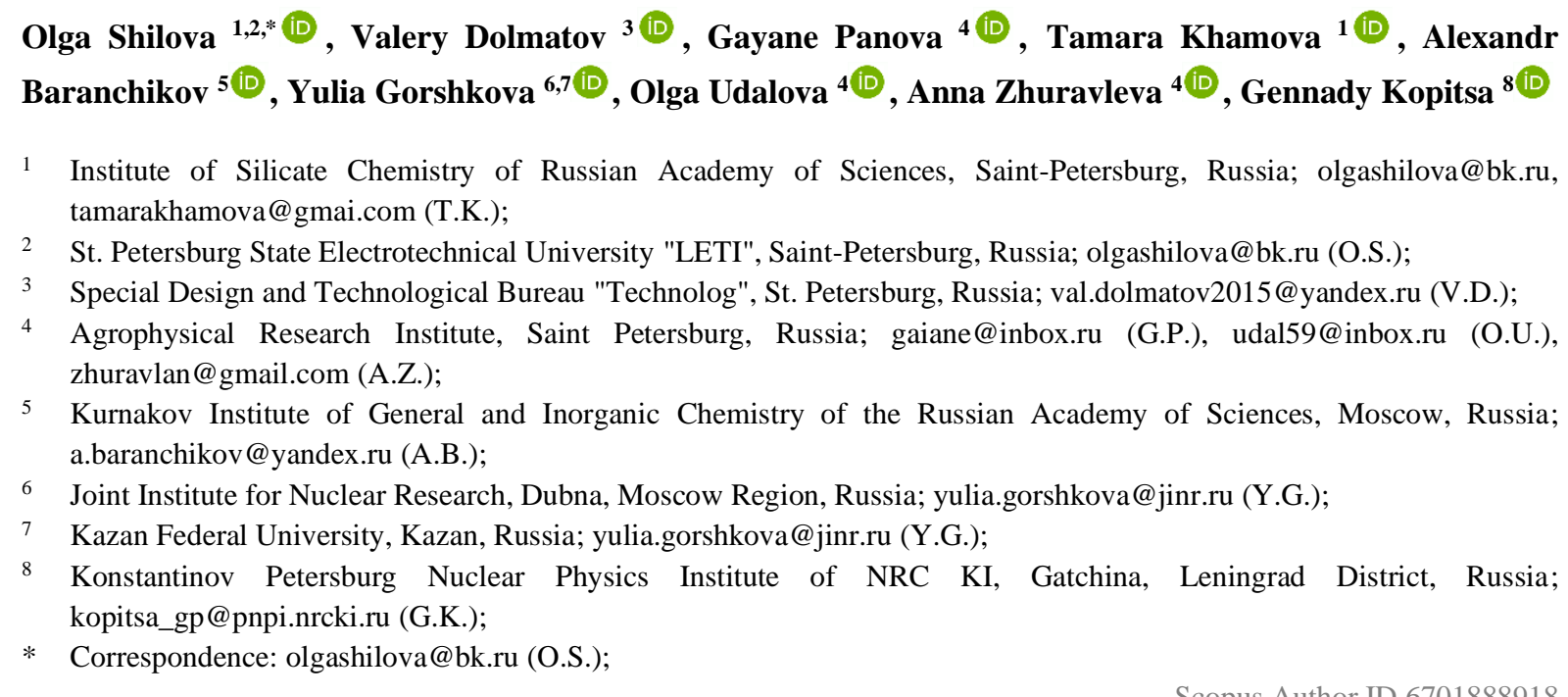

Received: 12.07.2021; Revised: 29.08.2021; Accepted: 5.09.2021; Published: 4.11.2021

\begin{abstract}
The batch of detonation nanodiamond (DB) containing impurities of B (DB-B) was obtained by explosion using TNT with hexagon (50/50). This DB-B contained $0.96 \mathrm{wt} \%$ of B. The obtained DBB nanopowder's morphological features, texture, and mesostructure were investigated by SEM, SAXS, and low-temperature nitrogen adsorption. We tested both aqueous suspensions and silica sols containing 2.5 wt. \% DND and 0.05-0.1 wt. \% of DB-B for the pre-sowing treatment of Chinese cabbage seeds. As a result, the reliable positive effect of an aqueous suspension of DB-B (0.05-0.1 wt.\%) was revealed on the following characteristics of seedlings (in relation to the control): the germination energy of Chinese cabbage seeds and germination increased by $\sim 50-70 \%$. Furthermore, a significant positive effect of DB-B on the morphological characteristics of Peking cabbage plants at the early stages of its development was revealed when using DB-B for pre-sowing seed treatment in combination with silica sol (an increase in the sprout length by $\sim 20 \%$ and root length by $\sim 50 \%$ in relation to the control) as well as the biomass of Chinese cabbage plants increased by $\sim 100 \%$ (20 days after planting the treated seeds).
\end{abstract}

Keywords: carbon nanomaterials; diamond batch; boron; pre-sowing seed treatment.

(C) 2021 by the authors. This article is an open-access article distributed under the terms and conditions of the Creative Commons Attribution (CC BY) license (https://creativecommons.org/licenses/by/4.0/).

\section{Introduction}

In the last decade, nanotechnology has been successfully used in agriculture [1-6]. Including nanoparticles of carbon materials (carbon nanotubes, fullerenes, fullerenols, and their adducts with amino acids, carboxylates, etc.) are being actively studied for use in agriculture [1,7-12]. Researchers are attracted by low concentrations of used carbon nanoparticles and their adducts, relative cheapness, and non-toxicity. Aqueous suspensions of carbon nanotubes, incl. functionalized with hydroxyl groups, solutions of fullerenols, and their adducts (i.g., with 
amino acids) can be used for pre-sowing seed treatment and the root environment and foliar treatment of vegetative plants. In general, such treatments promote better seed germination and plant growth, increase plant resistance to oxidative stress and high salt content in the soil, and increase the amount of biomass of various plants. The use of carbon nanomaterials as stimulants for the growth of plants and crops is of interest to the scientific community and industrialists. The mechanisms of the influence of carbon materials on the growth and development of plants are actively studied. At the same time, various factors such as size, shape, surface structure, solubility, and concentration of nanoparticles, including carbon nanomaterials, as well as the presence of functional groups, contribute significantly to plant digestibility, as well as to toxicity and pathology caused by their use [7,13]. Therefore, the use of carbon materials in agriculture requires a thorough preliminary study of both the properties of the materials themselves and the effect of their effect on each type of plant.

It is known that detonation nanodiamond (DND) has bactericidal and fungicidal properties [14-16]. DND is widely researched for medical purposes, particularly as drug delivery [17-19]. However, the use of nanodiamonds (DND) in agriculture is less well known. Large volumes of reagents are needed for agricultural applications, purification is less important, but it is important that they would be cheap. The detonation nanodiamond (DB) batch also has a scientific and practical interest since it is much cheaper than DND. The cost of DB is 3-5 times less than the cost of purified DND ( $\$ 300$ per $1 \mathrm{~kg})$. At the same time, it can have a whole range of useful properties.

Of particular interest are the DND and DB, enriched with various elements that give it new useful properties [20-22]. The DB has a very complex structure containing both DND proper and other non-diamond forms of carbon. DB doped with heteroatoms (i.g., B, Si, etc.) have an even more complex composition. The problem of studying such complex compositions is extremely urgent. The DB containing impurities B (DB-B) was obtained in the Special Design Bureau "Technolog" (St. Petersburg, Russia). The DB-B was synthesized by explosion using TNT with hexagon as precursors [23-25]. This object has not been studied enough. It was important to study the structure of the DB-B. It was interesting to test this DB-B for seeds presowing to study the effect on germination, growth, and development of plants.

Silicon compounds also promote plant growth and development [26-29]. Our earlier researches have shown that the treatment of seeds of spring barley and Chinese cabbage with silica sol is obtained by hydrolysis of tetraethoxysilane (TEOS), incl. with the addition of a number of elements useful for plants (in trace amounts) positively affects the development of plants in the early stages of development [30,31]. It was useful to compare the effect of DND and DB-B on plants, both in the form of aqueous suspensions and in combination with the TEOS-derived silica sols.

Thus, this work aimed to study the structure of the DB powders and test there for presowing treatment of seeds of Chinese cabbage, along with the treatment of seeds directly with DND, as well as in combination with TEOS-derived silica sols.

\section{Materials and Methods}

\subsection{Nanopowders synthesis.}

Diamond batch enriched with B (DB-B) was obtained by explosion using a mixture of TNT with hexagon. 
A non-crystalline amorphous powder containing boron was used as a dopant containing 92-94 wt.\% B and a density of $\sim 2.3 \mathrm{~g} / \mathrm{cm}^{3}$. This powder was obtained by sintering boric acid with magnesium, and then the sinter was treated at $70 \pm 2^{\circ} \mathrm{C}$ with a $15-20 \%$ hydrochloric acid solution. The precipitate was washed, dried, and calcined in a vacuum. [32].

The dopant (2.5 wt.\% B) was introduced into an explosive (TNT with hexogen). The mixture powders were thoroughly mixed and pressed at a pressure of $1500 \mathrm{~kg} / \mathrm{cm}^{2}$. The charges had a diameter of $60 \mathrm{~mm}$, a length of $107-110 \mathrm{~mm}$, and a mass of $0.5 \mathrm{~kg}$. The charges were detonated in an Alfa-2M explosive chamber with a volume of $2.14 \mathrm{~m}^{3}$. Each charge had a water shell (explosive: $\mathrm{H}_{2} \mathrm{O}=1: 10$ ). The resulting DB-B composition after the explosion prepared using both TNT with hexogen is presented in Table 1.

Table 1. Composition of boron-enriched diamond batch (DB-B).

\begin{tabular}{c|c|c|c|c}
\multirow{2}{*}{ Sample designation } & \multirow{2}{*}{ Charge } & \multicolumn{3}{|c}{ Content, wt.\% } \\
\cline { 3 - 5 } & & DND & Non-combustible impurities & Boron \\
\hline DB-B & TH 50/50 & 14.7 & 3.5 & 0.96 \\
Note: $\mathrm{TH}-$ a mixture of TNT with hexagen, DND - detonation nanodiamond.
\end{tabular}

To obtain the thermal-ammonia-treated detonation nanodiamond (DND-TAN), the diamond batch (DB) was subjected to nitric acid purification, namely: it was treated with $40 \%$ nitric acid at a temperature of $225-240^{\circ} \mathrm{C}$ for $1 \mathrm{~h}$ at $80-100 \mathrm{~atm}$. [33]. The obtained purified DNDs were washed from traces of acid to $\mathrm{pH}$ 6-7, then; aqueous ammonia was added to $\mathrm{pH}$ $11-12$, heated to $230^{\circ} \mathrm{C}$, and kept at this temperature for $1 \mathrm{~h}$; the pressure in the autoclave was 40-50 atm. [34]. DND, after thermal ammonia treatment, had nitrogen-containing functional groups on its surface. Such DND was designated as DND-TAN. After such treatment, the amount of incombustible impurities drops by 2-2.5 times relative to DND after nitric acid cleaning, and the size of the aggregates in the aqueous suspension decreases 2-3 times. In this regard, DND-TAN is preferably used directly in the form of an aqueous suspension. The structure and properties of DND-TAN are described in [25,35].

\subsection{Powder research methods.}

The obtained DB-B nanopowder's morphological features, texture, and mesostructure were investigated by SEM, SAXS, and low-temperature nitrogen adsorption.

The morphology of nanoparticles (size, shape, and degree of their aggregation) was studied by scanning electron microscopy (SEM), which was performed using a scanning electron microscope with a field emission cathode (FE-SEM) ZeissMerlin.

An experiment on small-angle neutron scattering (SANS) on DB-B was carried out on a YuMO spectrometer located at channel 4th of the IBR-2 pulsed reactor (Dubna, Russia) in a two-detector configuration using the time-of-flight method [36]. The flux of thermal neutrons was formed by a system of collimators so that the neutrons hitting the sample formed a beam of $14 \mathrm{~mm}$ in diameter with an intensity of up to $4 \times 10^{7}$ neutrons. As a result, the range of the transferred momentum $q$ was $6.5 \cdot 10^{-3} \div 0.4 \AA^{-1}(q=4 \pi \cdot \sin \theta / \lambda$, where $\lambda$ is the neutron wavelength and $\theta$ is the scattering angle), which corresponds to the analysis of the structure in the range of characteristic sizes from 10 up to 500 angstroms.

A sample of the DB-B was placed in an aluminum cell with a $1 \mathrm{~mm}$ depression. The processing of the initial experimental data was carried out by the SAS program [37], which allows the obtained spectrum to be normalized to an independent vanadium scatterer, taking 
into account the scattering from the setup and the aluminum cell, as well as the background of the hall [38].

Measurements of the specific surface area of the sample of the DB-B were performed by low-temperature nitrogen adsorption using QuantaChrome Nova 1200e analyzer. The powder was degassed at $150^{\circ} \mathrm{C}$ in a vacuum for $17 \mathrm{~h}$ prior to analysis. Based on the data obtained, the specific surface area $S_{\text {BET }}$ was calculated for the samples using the BrunauerEmmett-Teller model (BET) and the seven points method within the relative pressure range of $\mathrm{P} / \mathrm{P}_{0}=0.07 \div 0.25$ (where $\mathrm{P}_{0}$ is the saturation pressure). In addition, the calculation of the pore size distribution was carried out based on nitrogen isotherms using the Barrett-Joyner-Halenda (BJH) method.

\subsection{Seed treatment preparations.}

Both aqueous suspensions with DND or DB-B and silica sols with and without DND or DB-B were used for pre-sowing seed treatment. The aqueous suspensions of DND or a batch are of particular interest as precursors of composite materials or as biologically active additives since colloidal carbon nanoparticles in an aqueous dispersion medium are the most chemically reactive [39].

The silica sols differing in concentration ratios of the main components, the acidity of the medium, and modifying additives were prepared. Tetraethoxysilane $\mathrm{Si}(\mathrm{OEt})_{4}$ (TEOS), special purity grade; hydrochloric acid $(\mathrm{HCl})$, special purity grade, in the form of $0.25 \mathrm{~N}$ aqueous solution; potassium hydroxide $(\mathrm{KOH})$ high-purity grade, in the form of a $0.1 \mathrm{~N}$ aqueous solution were used as precursors for the preparation of silica sols.

DND-TAN in the form of a $3 \mathrm{wt} \%$ aqueous suspension or DB-B in the form of a powder was introduced into silica sols as modifying additives.

The following compositions were prepared: $0.08 \mathrm{~g}$ DND per $1 \mathrm{ml}$ of water or a silica sol (2.5 wt.\% DND); $0.002 \mathrm{~g} \mathrm{DB}-\mathrm{B}$ per $1 \mathrm{ml}$ of water or a silica sol (0.05 wt. \% DB-B), and $0.003 \mathrm{~g}$ per $1 \mathrm{ml}$ of water or a silica sol (0.1 wt. \% DB-B).

The preparation of silica sols was carried out according to a one-stage method of acidic or alkaline hydrolysis of TEOS with an excess of water.

The one-stage procedure consisted of sequential mixing of the initial components: $\mathrm{Si}(\mathrm{OEt})_{4}, 0.25 \mathrm{~N} \mathrm{HCl}$ and/or $0.1 \mathrm{~N} \mathrm{KOH}$. As a result, the silica sols were obtained. The description of these compositions is presented in Table 2. As a result, a silica sol was obtained, the composition of which is shown in Table 2.

Table 2. Compositions of silica sols and aqueous suspensions used for the pre-sowing treatment of Peking cabbage seeds

\begin{tabular}{c|c|c|c}
\multirow{2}{*}{ Designation } & \multicolumn{3}{|c}{ The ratio of the initial components } \\
\cline { 2 - 4 } & Si(OEt) $)_{\text {, vol.\% }}$ & $\mathbf{0 . 2 5 N ~ H C l , ~ v o l . \% ~}$ & $\mathbf{0 . 1}$ N KOH, vol.\% \\
\hline TEOS (1\%) pH 2-3 & 1 & 0.5 & - \\
\hline TEOS (1\%) pH 7-8 & 1 & 0.5 & 3.3
\end{tabular}

\subsection{Pre-sowing seed treatment.}

Pre-sowing seed treatment was carried out as a result of mixing for 10 minutes by simply shaking the seeds in containers with water (control) and the above solutions of substances and their compositions. The seeds were dried at room temperature in the air and then at $30^{\circ} \mathrm{C}$ for $60 \mathrm{~min}$ in an oven. Seed drying regimes corresponded to those specified in 
GOST 12038. Treated seeds were stored at room temperature before sowing. The repetition of the experiment was 400 seeds for each variant of the experiment.

\subsection{Procedure for assessing the biological activity of the tested substances.}

The effect of the tested substances on plants was evaluated in laboratory conditions and on a polygon with partial or complete regulation of microclimate conditions. Chinese cabbage of the Daqingkou variety (China, k-56), adapted to intensive plant artificial-light culture conditions, was the study's object. The seeds were obtained from the collections of the N.I. Vavilov All-Russian Institute of Plant Genetic Resources (VIR).

2.5.1. Methodology for determining the germination energy and germination capacity.

Control and treated with test seed treatment preparations Chinese cabbage seeds were germinated in Petri dishes $(10 \mathrm{~cm}$ in diameter) on filter paper moistened with $10 \mathrm{ml}$ of distilled water. The seed germination energy was assessed on the 3rd day, germination - on the 7th day; the length of shoots and roots of seedlings was also measured. The researches were carried out in accordance with the rules of the International Seed Testing Association (ISTA) and generally accepted methods. All experiments were repeated three times.

2.5.2. Methodology for assessing the effect of pre-sowing seed treatment on plant growth and development.

The study of the effect of pre-sowing treatment of the seeds of Chinese cabbage variety Daqingkou with the tested preparations on the growth and development of plants was carried out in a greenhouse with partially controlled microclimate conditions under natural illumination, an air temperature of $20-25^{\circ} \mathrm{C}$ during the day, $18-20^{\circ} \mathrm{C}$ at night, and relative humidity of $60-70 \%$. The plants were grown on a substrate based on high-moor peat with a low degree of decomposition with the addition of macro-and microelements in the composition of Knop nutrient solution. The moisture content of the substrate was maintained at $60 \%$ of the total moisture capacity. The plants were harvested at the age of 20 days. Plants whose seeds were treated with water served as control.

At the end of the growing season, the main plant growth and development indicators were taken into account.

Statistical data processing was carried out using Excel 2010 and Statistica 8 software (Stat-Soft, Inc., USA). The mean values of the studied indicators, confidence intervals, and coefficients of variation were determined. The significance of the differences between the variants was assessed using the methods of parametric statistics (Student's t-test). Differences between the options were considered significant at $\mathrm{p} \leq 0.05$.

\section{Results and Discussion}

\subsection{Boron-enriched diamond batch surface morphology.}

\subsubsection{Scanning electron microscopy data.}

The surface morphology of DB-B powder, as well as the change in the surface morphology of the Peking cabbage seeds as a result of pre-sowing treatment in DB-B aqueous 
suspension and in a silica sol with the addition of DB-B, can be estimated from SEM images in Figures 1 and 2.

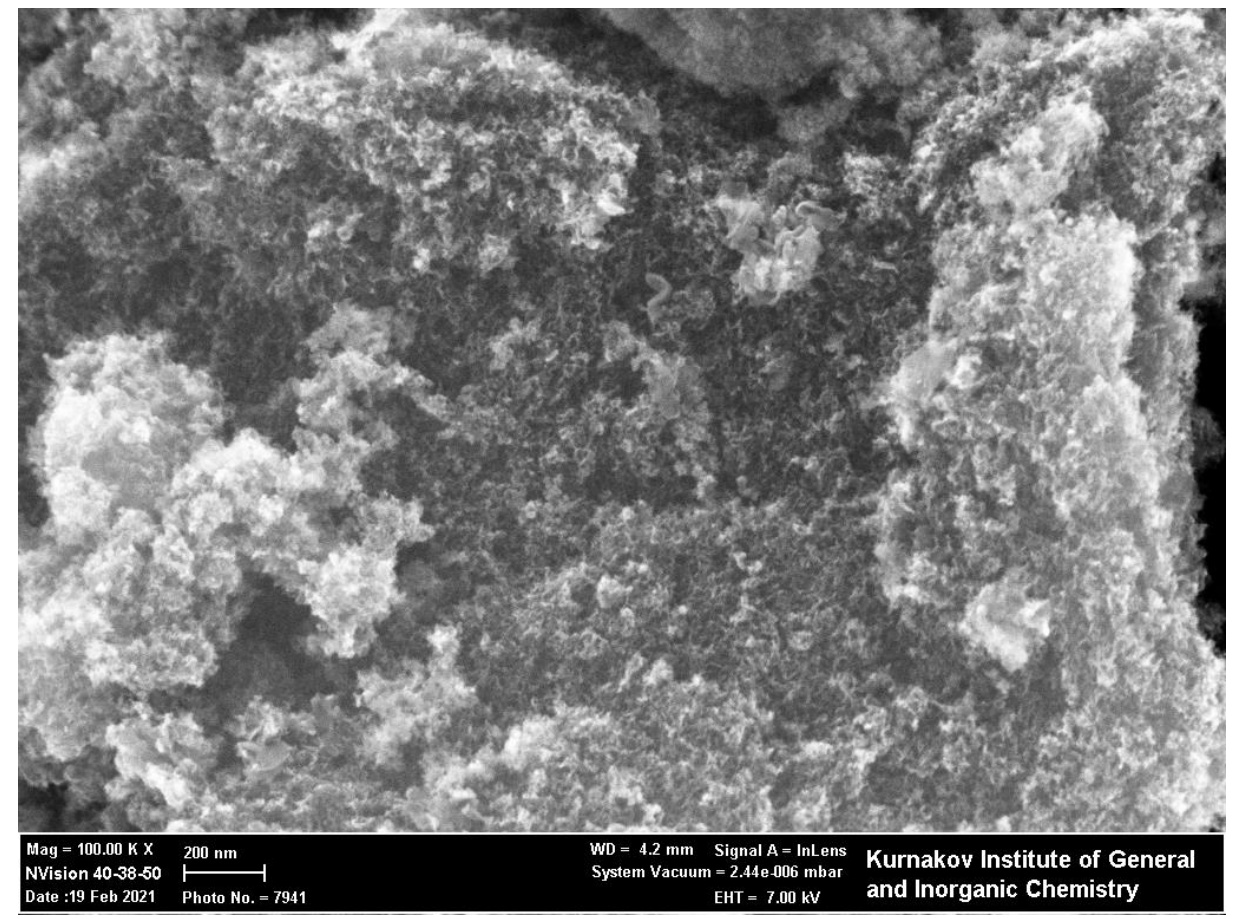

Figure 1. SEM image of DB-B powder.

DB-B powder consists of non-spherical, close to plate shape particles (Figure 1).

It can be stated that the state of the seed surface changed (Figure 2). As a result of the pre-sowing treatment of seeds, a thin film appears on their surface, consisting of DB-B nanoparticles and silica (in the case of using silica sols).
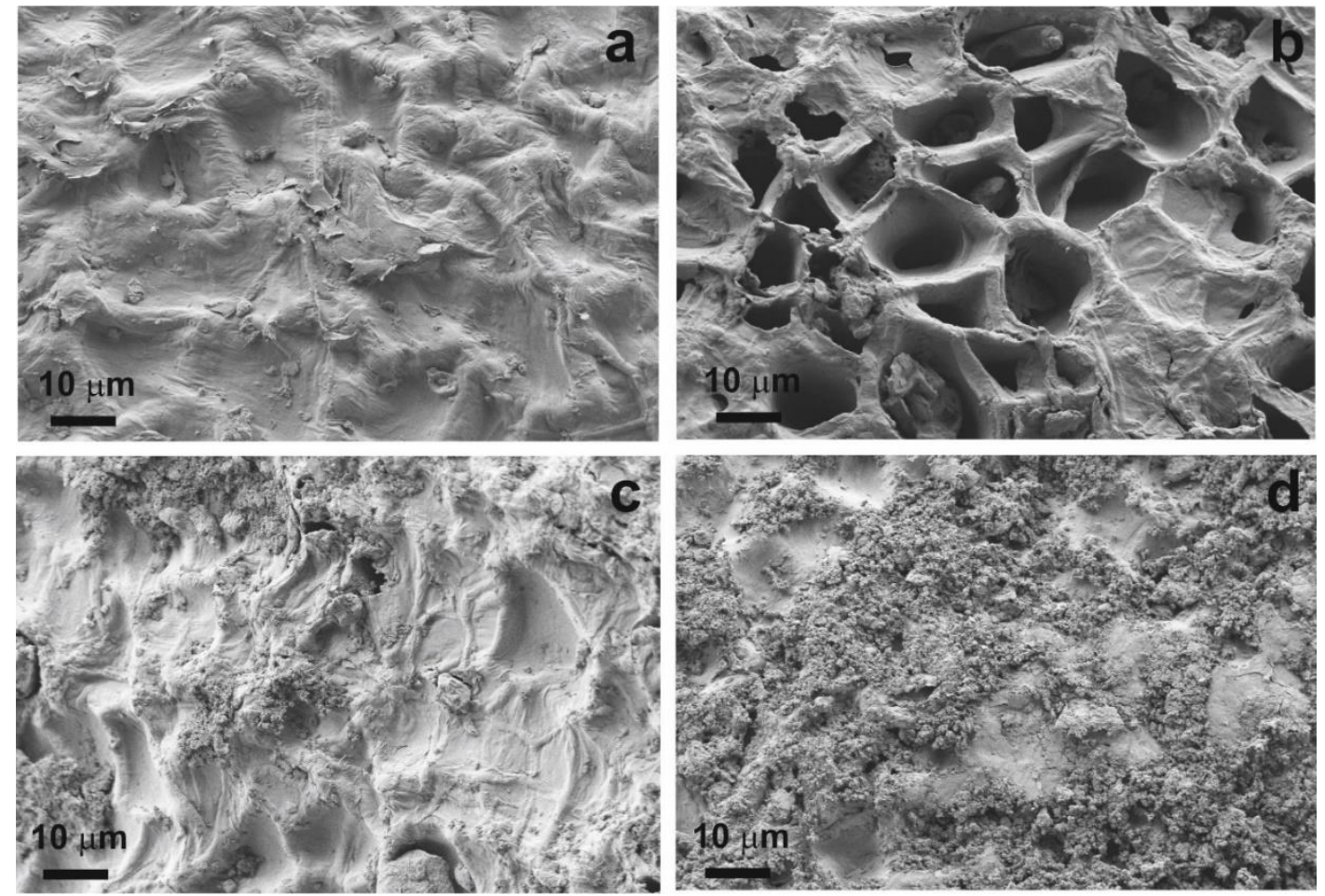

Figure 2. SEM image of the surface of Peking cabbage seeds without any treatment (a) and after treatment with TEOS-derived silica sol (1\%, pH 2-3) (b), an aqueous suspension of a diamond batch enriched with boron (0.1 wt.\% DB-B (c), and the silica sol with the addition of DB-B (0.1 wt.\%) (d). 
3.2. Boron-enriched diamond batch mesostructure.

3.2.1. Low-temperature nitrogen adsorption data.

The obtained isotherm (Figure 3 a) is characterized by pronounced capillarycondensation hysteresis and belongs to type IV according to the IUPAC classification (The International Union of Pure and Applied Chemistry Classification).

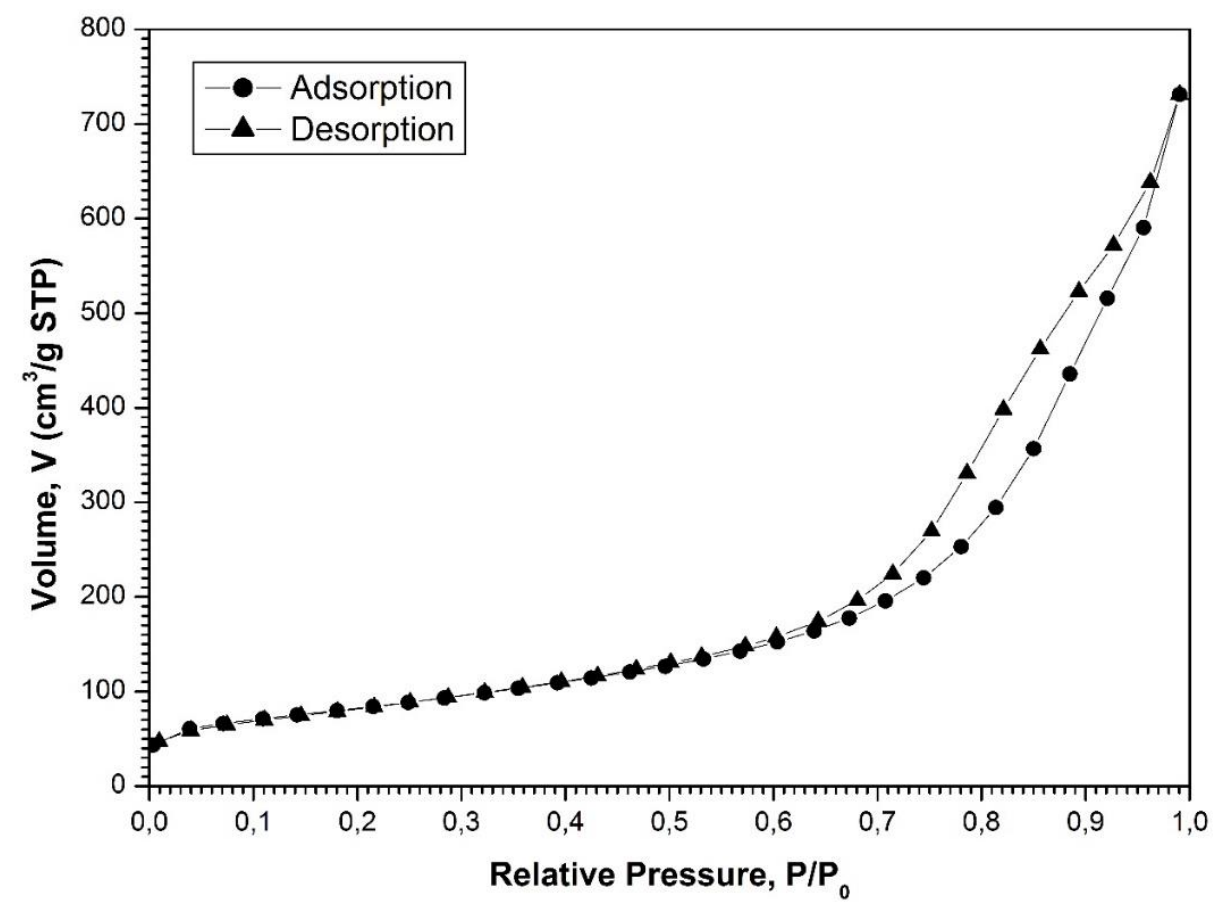

a

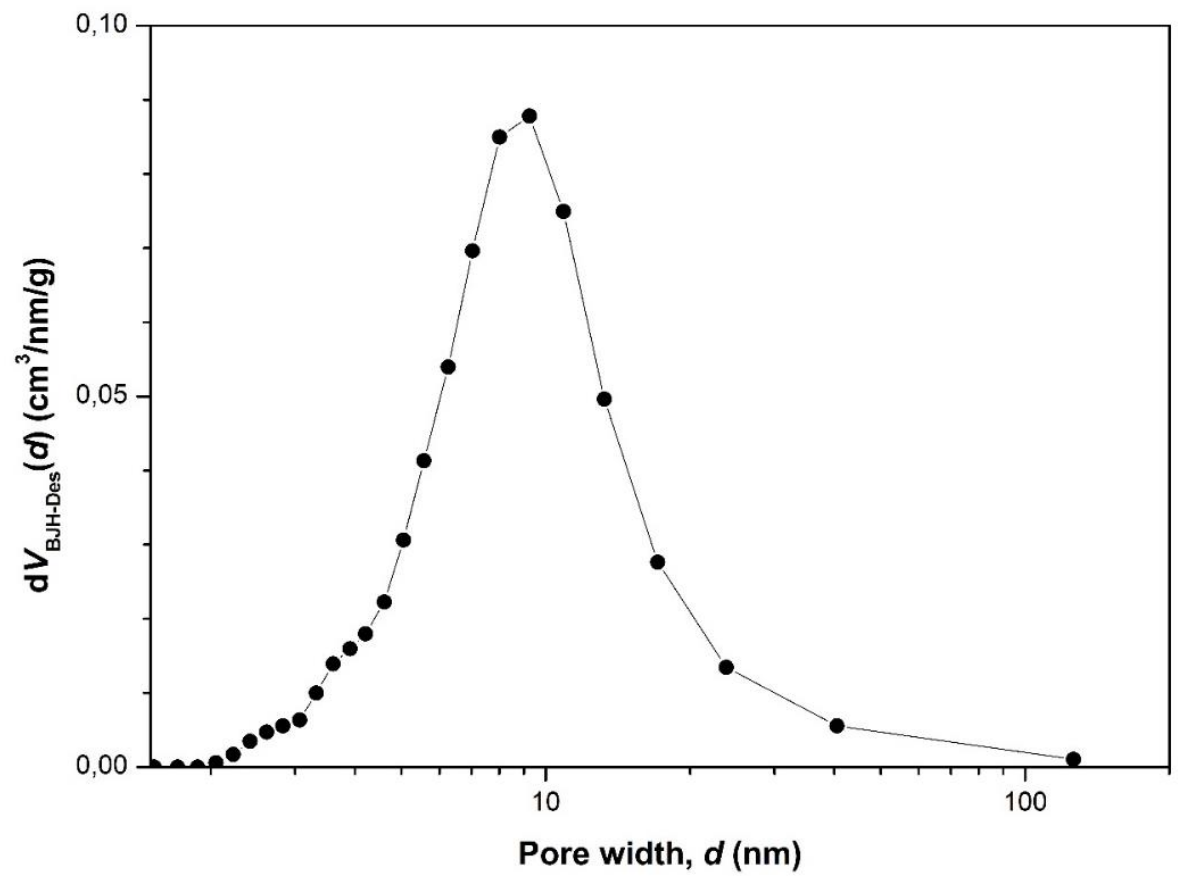

$\mathrm{b}$

Figure 3. Full nitrogen adsorption-desorption isotherm (a) and pore size distribution $\mathrm{dV}(\mathrm{d})$ obtained within the BJH model (b) for the DB-B powder.

The shape of the hysteresis loop for this sample corresponds to the classical H3 type according to the IUPAC classification, usually associated with the presence of slit-like pores 
typical for the materials consisting of flat particles. The hysteresis loop closes at a relative pressure $\mathrm{P} / \mathrm{P}_{0}$ significantly higher than 0.3 , which indicates the absence of the micropores in this sample.

Mathematical processing of the full nitrogen adsorption-desorption isotherm within the BJH model made it possible to obtain the pore size distributions shown in Fig. 3 b. It is clearly seen from this figure that the sample of the DB-B powder is characterized by a practically normal distribution of $d V(d)$ with a maximum of $d_{\mathrm{p}} \approx 9 \mathrm{~nm}$. The results of determining the texture parameters of DB-B powder are shown in Table 3.

Table 3. Textural parameters of the DB-B powder.

\begin{tabular}{c|c|c}
$S_{\mathrm{BET}}\left(\mathrm{m}^{2} / \mathrm{g}\right)$ & $V_{\mathrm{sp}}(P / P 0 \cong 0.995)\left(\mathrm{cm}^{3} / \mathrm{g}\right)$ & $d_{\mathrm{p}}(\mathrm{nm}) \mathrm{BJH}(\mathrm{des})$ \\
\hline $296 \pm 6$ & 1.14 & 9.3
\end{tabular}

Note: $S_{\mathrm{BET}}-$ specific surface area; $\mathrm{V}_{\mathrm{sp}}$ - specific pore volume; $\mathrm{d}_{\mathrm{p}}$ - average pore diameter.

\subsubsection{Data Small-Angle Neutron Scattering Data.}

Figure 4 shows the experimental log-log plot of neutron scattering cross sections $d \Sigma(q) / d \Omega$ versus the momentum transfer $q$ for DB-B powder. As can be seen from this figure, there are three different ranges in $q$ on the corresponding curves, in which the behavior of the small-angle scattering cross-section $\mathrm{d} \Sigma(q) / \mathrm{d} \Omega$ is very different.

The scattering in the region $q<0.35 \AA$ is characterized by the presence of two ranges on the corresponding curve $\mathrm{d} \Sigma(q) / \mathrm{d} \Omega: q>q_{\mathrm{c}}$ (Guinier region) and $q<q_{\mathrm{c}}$ (Porod region) with the point of crossover between them is $q_{\mathrm{c}} \approx 0.11 \AA^{-1}$ (the point of transition from one scattering regime to another) - where the scattering obeys the power laws $q^{-\Delta}$ with different values of exponents $\Delta=s$ and $n$, respectively.

This pattern is typical for scattering on porous systems (solid-phase - pore) consisting of randomly oriented non-spherical (anisodiametric) inhomogeneities, for example, for highly elongated or flattened particles or pores [40,41], which is consistent with the results obtained for this sample using scanning microscopy methods (Figure 1) and low-temperature nitrogen adsorption (Figure 4). In order to describe scattering in the Guinier region, which is determined by the size $R_{\mathrm{c}}$ and shape of scattering inhomogeneities, one should use the generalized relationship [42]:

$$
\frac{d \Sigma(q)}{d \Omega}=\frac{G}{q^{s}} \cdot \exp \left(-\frac{q^{2} R_{g}^{2}}{3-s}\right)
$$

where the amplitude $\mathrm{G}$ is directly proportional to the product of the number of inhomogeneity's in the scattering volume and the square of the average density $\rho$ of the scattering amplitudes on them [43], $R_{\mathrm{g}}$ is the radius of gyration of scattering inhomogeneities, and the parameter $s$ is determined by the shape of the scattering inhomogeneities. $s$ equals 0 for spherical objects, $s$ equals 1 for one-dimensional particles or pores, and $s$ equals 2 for two-dimensional inhomogeneities. The values of the parameter $s$ can be not only integer but also fractional, for example, if the scattering inhomogeneities have the shape of an ellipsoid of rotation or the presence of heterogeneities of various shapes in the system.

Since non-spherical items are defined not by one but by two characteristic dimensions (radius Rc and length $\mathrm{L}$ in the case of elongated inhomogeneities) or three (thickness $\mathrm{T}$, width $\mathrm{W}$, and length $\mathrm{L}$ for flattened inhomogeneities), the Guinier region can comprise two or three momentum transfer q ranges. The presence of only one power-law section in the Guinier region 
(Fig. 3) indicates that the length L (in the case of elongated inhomogeneities) or the width W (for flattened inhomogeneities) exceeds the maximum size that can be determined using the setup used in the experiment. Nevertheless, using the ratio $R_{\max } \approx 3.5 / q_{\min }$ [44], it is possible to estimate this size, which was $R_{\mathrm{c}}>550 \AA$.

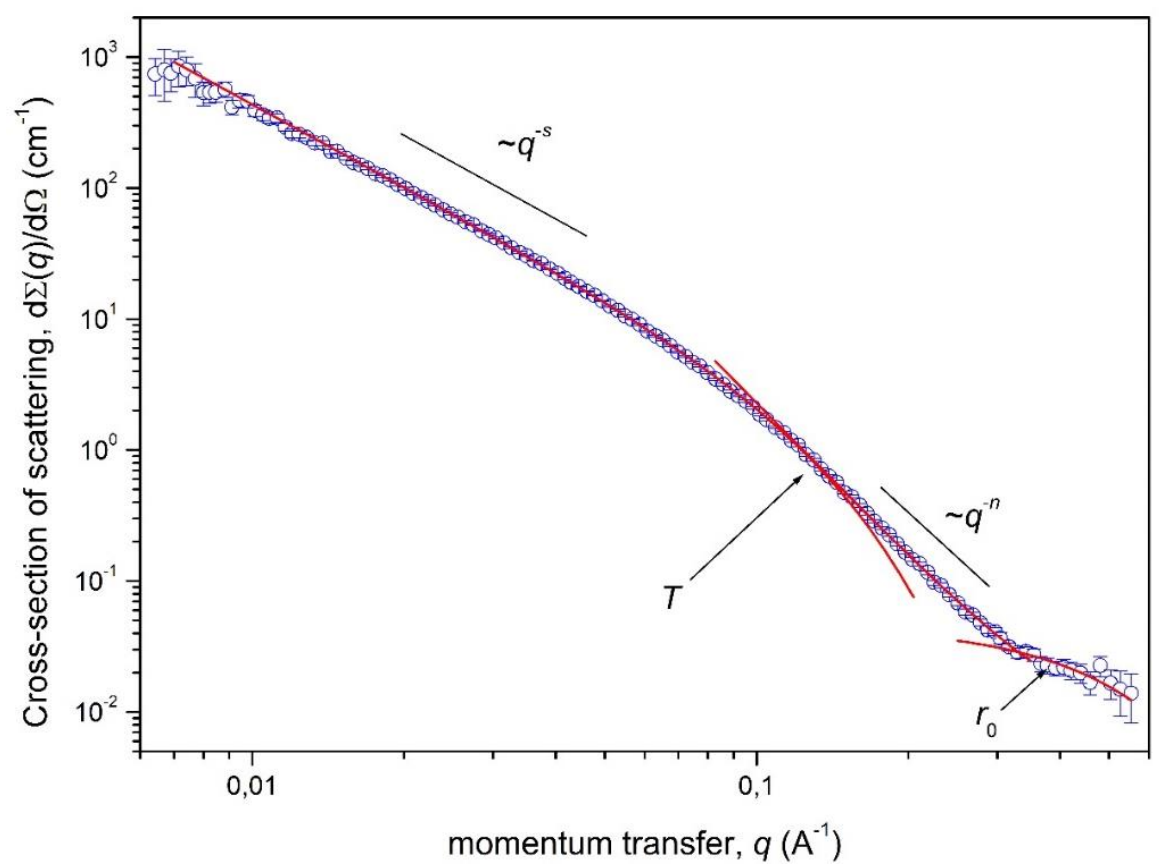

Figure 4. The dependence of the cross-section of small-angle neutron scattering $d \Sigma(q) / d \Omega$ versus the momentum transfer $\mathrm{q}$ for the powder DB-B. Solid lines result from the description of experimental data using formulas (1) and (2).

The values of the exponents of the degree $s$ and $n$, which were determined from the slope of the linear parts of the SANS curve in the ranges: $0.11<q \AA^{-1}$ and $0.11<q<0.35 \AA^{-}$ ${ }^{1},-$ are equal to $s=2.08 \pm 0.02$ and $n=3.92 \pm 0.04$, which corresponds to scattering on inhomogeneities (pores) of a flattened (slit-like) shape with a surface close to a smooth surface $\left(D_{\mathrm{s}}=6-n=2.08 \pm 0.04\right)$.

In view of the above, to analyze the scattering curve $\mathrm{d} \Sigma(q) / \mathrm{d} \Omega$ for DB-B powder, we use the generalized empirical Guinier-Porod model [42]:

In view of the above, to analyze the scattering curve $\mathrm{d} \Sigma(q) / \mathrm{d} \Omega$ for the powder DB-B, we use the generalized empirical Guinier-Porod model [42]:

$$
\begin{gathered}
\frac{d \Sigma(q)}{d \Omega}=\frac{G}{q^{s}} \cdot \exp \left(-\frac{q^{2} R_{g}^{2}}{3-s}\right) \text { at } q<q_{\mathrm{c}}, \\
\frac{d \Sigma(q)}{d \Omega}=\frac{B}{q^{n}} \quad \text { at } q_{\mathrm{c}}<q<0.35 \AA .
\end{gathered}
$$

Here $(3-s)$ is the dimension factor; $R_{\mathrm{g}}-$ is the gyration radius of non-spherical scattering inhomogeneities. For flattened inhomogeneities with thickness $T: R_{\mathrm{g}}=T / 12^{1 / 2} \cdot G-$ is the gyration radius of non-spherical scattering inhomogeneities. For flattened inhomogeneities with thickness [42, 45]; $B$ - the coefficient depending on the local structure of scattering inhomogeneities [46].

In the range of large $q>0.35 \AA^{-1}$, the appearance of the so-called "shoulder" on the scattering curve is observed, which indicates the presence of small spherical inhomogeneities in the system, possibly particles of non-combustible impurities, with a 
characteristic size $r_{0}$. In this case, the behavior of the scattering cross-section $d \Sigma(q) / d \Omega$ is also described by the Guinier approximation (1) with the parameters $\mathrm{s}=0$ and $\mathrm{r}_{0}=(5 / 3) 1 / 2 \times \mathrm{r}_{\mathrm{g}}[45]$.

To obtain the final results, Eq. (1) and Eq. (2) were convoluted with the instrumental resolution function. The experimental dependences of the differential scattering cross-section $d \Sigma(q) / d \Omega$ were processed using the least-squares method throughout the entire range under study. The results of the analysis are shown in Figure 3 and Table 4.

Table 4. Structural parameters of the powder DB-D obtained from the analysis of SANS data.

\begin{tabular}{c|c|c|c|c|c|c}
$\begin{array}{c}G \cdot 10^{2}, \\
\mathrm{~cm}^{-1} \cdot \AA^{-s}\end{array}$ & $s$ & $T, \AA$ & $\begin{array}{c}B \cdot 10^{4}, \\
\mathrm{~cm}^{-1} \cdot \AA^{-n}\end{array}$ & $n$ & $\begin{array}{c}G_{0} \cdot 10^{1}, \\
\mathrm{~cm}^{-1}\end{array}$ & $\begin{array}{c}r_{0}=(5 / 3)^{1 / 2} \mathrm{rg}_{\mathrm{g}}, \\
\AA\end{array}$ \\
\hline $4.6 \pm 0.3$ & $2.08 \pm 0.02$ & $24.9 \pm 0.4$ & $2.8 \pm 0.2$ & $3.92 \pm 0.04$ & $0.56 \pm 0.10$ & $4.7 \pm 0.5$
\end{tabular}

3.3. Biological activity of seed pre-sowing treatment preparations.

3.3.1. Morphometric indicators of plant development at early stages of development.

Pre-sowing treatment of Chinese cabbage seeds with aqueous suspensions of DND and DB-B separately or combined with TEOS-derived silica sols showed a predominantly positive effect on seed germination and growth parameters of plant seedlings (Table 5).

Table 5. Influence of seed pre-sowing treatment of Chinese cabbage variety Daqingkou (China, k-56) with tested preparations on their germination and growth characteristics of seven-day seedlings

\begin{tabular}{|c|c|c|c|c|c|c|c|c|}
\hline \multirow{2}{*}{$\begin{array}{l}\text { Seed treatment } \\
\text { preparations }\end{array}$} & \multicolumn{2}{|c|}{ Germination energy } & \multicolumn{2}{|c|}{ Germination } & \multicolumn{2}{|c|}{ Sprout length } & \multicolumn{2}{|c|}{ Root length } \\
\hline & $\%$ & $\begin{array}{c}\% \text { to } \\
\text { control }\end{array}$ & $\%$ & $\begin{array}{c}\% \text { to } \\
\text { control }\end{array}$ & $\mathbf{c m}$ & $\begin{array}{c}\% \text { to } \\
\text { control }\end{array}$ & $\mathbf{c m}$ & $\begin{array}{l}\% \text { to } \\
\text { control }\end{array}$ \\
\hline $\mathrm{H}_{2} \mathrm{O}$ (control) & 49 & 100 & 48 & 100 & $2,3 \pm 0,2$ & 100 & $3,9 \pm 0,7$ & 100 \\
\hline $\begin{array}{c}\text { Aqueous } \\
\text { suspension } \\
2.5 \% \text { DND-TAN }\end{array}$ & $40 *$ & $82 *$ & $40 *$ & $83^{*}$ & $2,6 \pm 0,3$ & 113 & $4,8 \pm 0,9$ & 123 \\
\hline $\begin{array}{c}\text { Aqueous } \\
\text { suspension } \\
0.05 \% \text { DB-B }\end{array}$ & $84 *$ & $171^{*}$ & $80 *$ & $166^{*}$ & $2,1 \pm 0,1$ & 91 & $5,2 \pm 0,2 *$ & $133^{*}$ \\
\hline $\begin{array}{c}\text { Aqueous } \\
\text { suspension } \\
0.1 \% \text { DB-B }\end{array}$ & $76^{*}$ & $155^{*}$ & $72 *$ & $150^{*}$ & $2,4 \pm 0,1$ & 104 & $5,3 \pm 0,6^{*}$ & $136^{*}$ \\
\hline $\begin{array}{c}\text { Silica sol } \\
1 \% \text { TEOS } \\
\text { pH 7-8 }\end{array}$ & 53 & 108 & 51 & 106 & $2,3 \pm 0,2$ & 100 & $5,0 \pm 0,7$ & 128 \\
\hline $\begin{array}{c}\text { Silica sol } \\
1 \% \text { TEOS }+0.1 \% \\
\text { DB-B } \\
\text { pH 7-8 }\end{array}$ & $33 *$ & $67 *$ & 43 & 90 & $2,8 \pm 0,2^{*}$ & $122 *$ & $5,8 \pm 0,7^{*}$ & $149^{*}$ \\
\hline
\end{tabular}

Aqueous suspensions of DB-B (0.05-0.1 wt.\%) had a positive effect on germination energy and germination capacity. Their efficiency, according to this indicator, is significantly higher than for DND-TAN suspension (2.5 wt.\%). The sizes of sprouts and roots turned out to be the highest when seeds were treated with silica sol based on TEOS ( 1 vol\%, pH 7-8) with the addition of DB-B $(0.1 \mathrm{wt} \%)$. In other cases, approximately the same effect was noted.

The positive effect of pre-sowing treatment of Chinese cabbage seeds with an aqueous suspension of DB-B (0.1 wt.\%) and TEOS-derived silica sol on the growth and development of plants at the early stages of development persists for 20 days of plant cultivation (Table 6). 
Table 6. Morphometric parameters of plants of Chinese cabbage variety Daqingkou (China, k-56), the seeds of which were pre-sowing treated with tested preparations (plant age 20 days).

\begin{tabular}{|c|c|c|c|c|c|c|c|}
\hline \multirow[b]{2}{*}{$\begin{array}{l}\text { Pre-sowing treatment } \\
\text { preparations }\end{array}$} & \multirow{2}{*}{$\begin{array}{l}\text { Diameter, } \\
\text { cm }\end{array}$} & \multirow[b]{2}{*}{ Height, cm } & \multirow[b]{2}{*}{$\begin{array}{l}\text { Number of } \\
\text { leaves }\end{array}$} & \multirow[b]{2}{*}{$\begin{array}{c}\text { Leaf length, } \\
\mathrm{cm}\end{array}$} & \multirow[b]{2}{*}{$\begin{array}{l}\text { Leaf width, } \\
\mathrm{cm}\end{array}$} & \multicolumn{2}{|c|}{ Wet weight } \\
\hline & & & & & & g & $\begin{array}{c}\% \text { of } \\
\text { control }\end{array}$ \\
\hline $\mathrm{H}_{2} \mathrm{O}$ (control) & $19,1 \pm 2,6$ & $8,3 \pm 1,2$ & $6,6 \pm 0,4$ & $13,8 \pm 2,5$ & $7,6 \pm 0,9$ & $4,5 \pm 2,2$ & 100 \\
\hline $\begin{array}{l}\text { Heteroauxin } 10 \mathrm{mg} / \mathrm{L} \text { (reference } \\
\text { for comparison) }\end{array}$ & $23,8 \pm 2,2$ & $13,4 \pm 2,0 * *$ & $7,4 \pm 0,8$ & $18,6 \pm 2,6$ & $9,0 \pm 1,2$ & $7,4 \pm 2,9 * *$ & $164 * *$ \\
\hline $\begin{array}{c}\text { Aqueous suspension } \\
0.1 \% \text { DB-B }\end{array}$ & $21,1 \pm 2,5$ & $10,1 \pm 1,2$ & $7,5 \pm 0,6$ & $16,8 \pm 2,2$ & $8,3 \pm 0,6$ & $6,6 \pm 2,1 * *$ & $147 * *$ \\
\hline Silica sol, $1 \%$ TEOS, $\mathrm{pH} 7-8$ & $22,1 \pm 2,1$ & $10,2 \pm 1,6$ & $6,7 \pm 0,4$ & $16,7 \pm 2,0$ & $8,7 \pm 0,7$ & $6,6 \pm 2,2 * *$ & $146,7 * *$ \\
\hline $\begin{array}{c}\text { Silica sol, } 1 \% \text { TEOS }+0.1 \% \\
\text { DB-B, pH 7-8 }\end{array}$ & $20,1 \pm 3,9$ & $10,1 \pm 2,3$ & $7,0 \pm 0,1$ & $16,7 \pm 2,7$ & $9,1 \pm 0,4 * *$ & $8,9 \pm 3,8 * *$ & $198 * *$ \\
\hline
\end{tabular}

Note: The values are significantly different from the control at the $5 \%$ significance level is marked with the sign $(*)$.

A pronounced synergistic effect on the formation of plants with higher biomass and the growth rates of plants from using DB-B additive together with silica sol may be noted.

\section{Conclusions}

The advanced carbon nanopowder - the boron-enriched diamond batch (DB-B)- was synthesized by detonating TNT with hexagen (50/50). The resulting DB-B contained $14.7 \mathrm{wt} . \%$ DND, 0.96 wt.\% B and 3.5 wt.\% of incombustible impurities. According to SEM and lowtemperature nitrogen adsorption data, DB-B powder had a high specific surface area $S_{B E T} \sim 300$ $\mathrm{m}^{2} / \mathrm{g}$, consisting of lamellar mesoporous nanoparticles, with slit pores of the pore average size $\sim 9 \mathrm{~nm}$, practically without micropores. The SANS data confirmed the results obtained by other research methods. The DB-B powder consisted of randomly oriented non-spherical (anisodiametric) inhomogeneities, highly elongated or flattened particles (and/or pores). The size of carbon nanoparticles can be characterized by the following parameters: thickness $\mathrm{T}$ $2.5 \mathrm{~nm}$ and width $(\mathrm{W})$ or length $(\mathrm{L})>55 \mathrm{~nm}$. Some spherical nanoparticles $(\sim 0.5 \mathrm{~nm})$ were found, which are apparently formed by incombustible impurities. DB-B was tested as a biologically active additive (0.05-0.1 wt.\%) for the pre-sowing treatment of Chinese cabbage seeds (variety Daqingkou, China, k-56). As a result, the reliable positive effect of an aqueous suspension of DB-B (0.05-0.1 wt.\%) was revealed on the following characteristics of seedlings (in relation to the control): the germination energy of Chinese cabbage seeds and germination increased by $\sim 50-70 \%$. A significant positive effect of DB-B on the morphological characteristics of Chinese cabbage plants at the early stages of its development was revealed when using DB-B for pre-sowing seed treatment in combination with silica sol (an increase in the sprout length by $\sim 20 \%$ and root length by $\sim 50 \%$ in relation to the control) as well as the biomass of plants Chinese cabbage increased by $\sim 100 \%$ (20 days after planting the treated seeds).

\section{Funding}

This research was funded by the Russian Science Foundation, grant number 19-13-00442 in terms of studying the structure and properties of carbon materials.

\section{Acknowledgments}

The SEM measurements were performed using shared experimental facilities supported by IGIC RAS (Moscow, Russia) state assignment. The authors are grateful to the Joint Institute 
for Nuclear Research (Russia) for the possibility of extended performance of the SANS experiment at the IBR-2 pulsed reactor (Dubna, Russia).

\section{Conflicts of Interest}

The authors declare no conflict of interest.

\section{References}

1. Pérez-de-Luque, A. Guest Edited Collection: Nanotechnology in agriculture. Sci. Rep. 2020, 10, 15738, https://doi.org/10.1038/s41598-020-73198-7.

2. Usman, M.; Farooq, M.; Wakeel, A.; Nawaz, A.; Cheema, S.A.; Rehman, H.U.; Ashraf, I.; Sanaullah, M. Nanotechnology in agriculture: Current status, challenges and future opportunities. Sci. Total Environ. 2020, 721, 137778, https://doi.org/10.1016/j.scitotenv.2020.137778.

3. Singh, R.P.; Handa, R.; Manchanda, G. Nanoparticles in sustainable agriculture: An emerging opportunity, J. of Contr. Rel. 2020, 329, 1234-1248, https://doi.org/10.1016/j.jconrel.2020.10.051.

4. Paramo, L.A.; Feregrino-Pérez, A.A.; Guevara, R.; Mendoza, S.; Esquivel, K. Nanoparticles in Agroindustry: Applications, Toxicity, Challenges, and Trends. Nanomat. 2020, 10, 1654, https://doi.org/10.3390/nano10091654.

5. Samrot, A.V.; Sahithya, C. Sai; Selvarani, J.; Purayila, S.K.; Ponnaiah, P. A review on synthesis, characterization and potential biological applications of superparamagnetic iron oxide nanoparticles. Cur. Res. in Green and Sust. Chem. 2021, 4, 100042, https://doi.org/10.1016/j.crgsc.2020.100042.

6. Chaudhary, I.J.; Singh, V. Titanium dioxide nanoparticles and its impact on growth, biomass and yield of agricultural crops under environmental stress: A review. Res. J. of Nanosci. and Nanotechn. 2020, 10, 1-8, https://doi.org/10.3923/rjnn.2020.1.8.

7. Dinesh, K.P.; Hye-Been, K.; Sayan, D.D.; Keya, G.; Ki-Taek, L. Carbon Nanotubes-Based Banomaterials and Their Agricultural and Biotechnological Applications. Mater. 2020, 13, 1679-1707, https://doi.org/10.3390/ma13071679.

8. Panova, G.G.; Kanash, E.V.; Semenov, K.N.; Charykov, N.A.; Khomyakov, Yu. V.; Anikina, L.M.; Artem'eva, A.M.; Kornyukhin, D.L.; Vertebnyi, V.E.; Sinyavina, N.G.; Udalova, O.R.; Kulenova, N.A.; Blokhina, S.Yu. Fullerene Derivatives Influence Production Process, Growth and Resistance to Oxidative Stress in Barley and Wheat Plants. Sel'skokh. Biolog. 2018, 53, 38-49, https://doi.org/10.15389/agrobiology.2018.1.38eng.

9. Khodakovskaya, M.; Dervishi, E.; Mahmood, M.; Xu, Y.; Li, Z.;Watanabe, F.; Biris, A.S. Carbon Nanotubes are able to Penetrate Plant Seed Coat and Dramatically Affect Seed Germination and Plant Growth. ACS Nano. 2009, 3, 3221-3227, https://doi.org/10.1021/nn900887m.

10. Rudakiya, D.; Patel, Y.; Chhaya, U.; Gupte, A. Carbon Nanotubes in Agriculture: Production, Potential, and Prospects. In: Nanotechnology for Agriculture. Panpatte, D., Jhala, Y. Ed. Springer: Singapore, 2019; $121-$ 130, https://doi.org/10.1007/978-981-32-9370-0_8.

11. Shojaei, T.R.; Mohamad Amran Mohd Salleh, M.A.M.; Tabatabaei, M; Mobli, H.; Aghbashlo, M.; Rashid, S.A.; Tan, T. Chapter 11-Applications of Nanotechnology and Carbon Nanoparticles in Agriculture. In: Synthesis, Technology and Applications of Carbon Nanomaterials (Micro and Nano Technologies). Rashid, S.A; Othman, R.N.I.R. Hussein, M.Z. Eds. Elsevier, 2019; 247-277, https://doi.org/10.1016/B978-0-12815757-2.00011-5.

12. Yuvaraj, M.; Subramanian, K.S. Carbon sphere-zinc sulphate nanohybrids for smart delivery of zinc in rice (Oryza sativa L). Sci. Rep. 2021, 11, 9508, https://doi.org/10.1038/s41598-021-89092-9.

13. Churilov, D; Churilova, V.; Stepanova, I.; Polischuk, S.; Gusev, A.; Zakharova, O.; Arapov, I.; Churilov, G. Size-Dependent Biological Effects of Copper Nanopowders on Mustard Seedlings. IOP Conf. Series: Earth and Environmental Science. 2019, 392, 012008, https://doi.org/10.1088/1755-1315/392/1/012008.

14. Gruen, D.M.; Shenderova, O.A.; Vul, A.Y. Synthesis, Properties and Applications of Ultrananocrystalline Diamond; Springer-Verlag: Berlin/Heidelberg, 2005, https://doi.org/10.1007/1-4020-3322-2.

15. Dolmatov, V.Y. Detonation-Synthesis Nanodiamonds: Synthesis, Structure, Properties and Applications. Russ. Chem. Rev. 2007, 76, 339-360, https://doi.org/10.1070/rc2007v076n04abeh003643. 
16. Khamova, T.V.; Shilova, O.A.; Vlasov, D.Yu.; Ryabusheva, Yu.V.; Mikhal'chuk, V.M.; Ivanov, V.K.; FrankKamenetskaya, O.V.; Marugin, A.M.; Dolmatov, V.Yu. Bioactive Coatings Based on Nanodiamond Modified Epoxy Siloxane Sols for Stone Materials. Inorg. Mater. 2012, 48, 702-708, https://doi.org/10.1134/S0020168512060052.

17. Turcheniuk, K.; Mochalin, V.N. Biomedical Applications of Nanodiamond (Review). Nanotech. 2017, 28252001, https://doi.org/10.1088/1361-6528/aa6ae4.

18. Berdichevskiy, G.M.; Vasina, L.V.; Ageev, S.V.; Meshcheriakov, A.A.; Galkin, M.A.; Ishmukhametov, R. R.; Nashchekin, A.V.; Kirilenko, D.A.; Petrov, A.V.; Martynova, S.D.; Semenov, K.N.; Sharoyko, V.V. A Comprehensive Study of Biocompatibility of Detonation Nanodiamonds. J. Molec. Liq. 2021, 332, 115763, https://doi.org/10.1016/j.molliq.2021.115763.

19. Dolmatov, V.Yu.; Shames, A.I.; Ōsawa, E.; Vehanen, A.; Myllymäki, V.; Dorokhov, A.O.; Marchukov, V. A.; Kozlov, A.C.; Naryzhny, S.Yu., Smirnova, A.Z. Detonation nanodiamonds: from synthesis theory to application practice. J. Adv. Mater. Technol. 2021, 6, 54-80, https://doi.org/10.17277/jamt.2021.01.pp.054080 .

20. Terada, D.; Segawa, T.F.; Shames, A.I.; Onoda, S.; Ohshima, T.; Sawa, E.O.; Igarashi, R.; Shirakawa, M. Monodisperse Five-Nanometer-Sized Detonation Nanodiamonds Enriched in Nitrogen-Vacancy Centers. ACS Nano. 2019, 13, 6461-6468, https://doi.org/10.1021/acsnano.8b09383.

21. Panich, A.M.; Shames, A.I.; Goren, S.D.; Yudina, E.Yu.; Aleksenskii, A.E.; Vul', A.Ya. Examining relaxivities in suspensions of nanodiamonds grafted by magnetic entities: comparison of two approaches. Magn Reson Mater Phy. 2020, 33, 885-888, https://doi.org/10.1007/s10334-020-00847-3.

22. Sushchev, V.G.; Dolmatov, V.Yu.; Malygin, A.A.; Marchukov, V.A.; Korolev, K.M.; Dorokhov, A.O. CoreShell Composites Based on Partially Oxidized Blend of Detonation Synthesis Nanodiamonds. Rus. J. of App. Chem. 2020, 93, 660-670, https://doi.org/10.1143/S1070427220050067.

23. Burkat, G.K.; Dolmatov, V.Yu.; Aleksandrova, G. S.; Osmanova, E. D.; Myllymäki, V.; Vehanen, A. The process of Electrochemical Deposition of Zinc in the Presence of Boron-doped Detonation Nanodiamonds. J. Superhard Mater. 2017, 39, 221-225, https://doi.org/10.3103/S1063457617040013.

24. Dolmatov, V.Yu.; Rudenko, D.V.; Burkat, G.K.; Aleksandrova, A.S.; Vul, A.Yu.; Aleksenskii, A.E.; Kozlov, A.S.; Myllymäki, V.; Vehanen, A.; D'yakov, I.A.; et al. A Study of the Process of Gold Plating from Citrate and Phosphate Electrolytes in the Presence of Modified Detonation Nanodiamonds. J. Superhard Mater. 2019, 41, 169-177, https://doi.org/10.3103/S1063457619030043.

25. Dolmatov, V.Yu.; Ozerin, A.N.; Kulakova, I.I.; Bochechka, O.O.; Lapchuk, N.M.; Myllymäki, V.; Vehanen, A. Detonation Nanodiamonds: New Aspects in the Theory and Practice of Synthesis, Properties and Applications. Russ. Chem. Rev. 2020, 89, 1428-1462, https://doi.org/10.1070/RCR4924.

26. Matychenkov, V.V.; Bocharnikova, E.A.; Kosobryukhov, A.A.; Bil', K.Ya., About Mobile Forms of Silicon in Plants. Dokl. Akad. Nauk. 2008, 418, 279-281.

27. Slastya, I.V. Use of Silicon Compounds as a Factor of Raising Spring Barley cultivars productivity under water stress. Sel'skokhozyaistvennayaBiologiya [Agricultural Biology], 2013, 2, 109-119, https://doi.org/10.15389/agrobiology.2013.2.109eng.

28. Kulikova, A.Kh.; Kozlov, A.V.; Toigildin, A.L. Influence of Silicon Containing Preparations on Agrochemical Properties of Sod and Podzolic Soil and Yielding Capacity of Crops. Res. J. of Pharm., Biolog. and Chem. Sci. 2018, 9, 432-436.

29. Selivanova, M.V.; Romanenko, E.S.; Aysanov, T.S.; Mironova, E.A.; Esaulko, N.A.; German, M.S. Efficiency of Application of Silicon-Containing Fertilizers in Low-Volume Cucumber Growing Technology Cyborg F1. Vegetable crops of Russia. 2020, 6, 25-30, https://doi.org/10.18619/2072-9146-2020-6-25-30.

30. Shilova, O.A.; Khamova, T.V.; Panova, G.G.; Anikina, L.M.; Artem'eva, A.M.; Kornyukhin, D.L. Using the Sol-Gel Technology for the Treatment of Barley Seeds. Glass Phys. and Chem. 2018, 44, 26-32, https://doi.org/10.1134/S108765961801011X.

31. Shilova, O.A.; Khamova, T.V.; Panova, G.G.; Anikina, L.M.; Udalova, O.R.; Galushko, A.S.; Kornyukhin, D.L.; Artemyeva, A.M., Baranchikov, A.E. Synthesis and Research of Functional Layers Based on Titanium Dioxide Nanoparticles and Silica Sols Formed on the Surface of Seeds of Chinese Cabbage. Russ. J. Appl. Chem. 2020. 93, 25-34, https://doi.org/10.1134/S1070427220010036.

32. Plyshevskij, Y.S.; Kerkher, T.E.; Knyshev, E.A.; Lipinskij I.E.; Vinogradov, A.A. Method of Amorphous Boron Production. Inventor's Sertificate No. 831727SU/ No. 2716750, priority: 1979.01.25; filed: 
1981.05.23. https://yandex.ru/patents/doc/SU831727A1_19810523. Courtesy of the Federal Institute of Industrial Property (FIPS). Date of access: 20.06.2021.

33. Dolmatov, V.J.; Marchukov, V.A.; Sushchev, V.G.; Veretennikova, M.V. Method of Preparing Stable Suspension of Detonation Nanodiamonds. Patent RU 2384524, March 20, 2010.

34. Dolmatov, V.J.; Sushchev, V.G.; Marchukov, V.A. Method for Separating Synthetic Ultrafine Diamonds. Patent RU 2109683, March 27, 1998.

35. Dolmatov, V.Yu.; Shames, A.I.; Ōsawa, E.; Vehanen, A.; Myllymäki, V.; Dorokhov, A.O.; Marchukov, V. A.; Kozlov, A.C.; Naryzhny, S.Yu.; Smirnova, A.Z. Detonation Nanodiamonds: From Synthesis Theory to Application Practice. J. Advan. Mater. and Techn.. 2021, 6, 54-80, https://doi.org/10.17277/jamt.2021.01.pp.054-080.

36. Kuklin, A.I.; Islamov, A.Kh.; Gordeliy, V.I. Scientific Reviews: Two-Detector System for Small-Angle Neutron Scattering Instrument. Neutron News. 2005, 16, 16-18, https://doi.org/10.1080/10448630500454361.

37. Soloviev, G.; Solovieva, T.M.; Kuklin, A.I. SAS - Package for Small-Angle Neutron Scattering Data Treatment. Program Library JINRLIB. Joint Institute for Nuclear Researchhttp://wwwinfo.jinr.ru/programs/jinrlib/sas/indexe.html (accessed on 21.06.2021).

38. Ostanevich, Yu. M. Time-of-Fight Small-Angle Scattering Spectrometers on Pulsed Neutron Sources. Makromol. Chem. Macromol. Symp. 1988, 15, 91-103, https://doi.org/10.1002/masy.19880150107.

39. Shvidchenko, A.V.; Eidelman, E.D.; Vul', A.Ya.; Kuznetsov, N.M.; Stolyarova, D.Yu.; Belousov, S.I.; Chvalun, S.N. Colloids of detonation nanodiamond particles for advanced applications. Adv. Colloid Interfac. 2019, 268, 64-81, https://doi.org/10.1016/j.cis.2019.03.008.

40. Baranchikov, A.E.; Kopitsa, G.P.; Yorov, Kh.E.; Sipyagina, N.A.; Lermontov, S.A.; Pavlova, A.A.; Kottsov, S.Yu.; Garamus, V.M.; Ryukhtin, V.; Ivanov, V.K. $\mathrm{SiO}_{2}-\mathrm{TiO}_{2}$ Binary Aerogels: A Small-Angle Scattering Study. Rus. J. Inorg. Chem. 2021, 66, 874-882, https://doi.org/10.1134/S003602362106005X.

41. Kozlova, T.O.; Baranchikov, A.E., Daniil A. Kozlov, D.A.; Gavrikov, A.V.; Kopitsa, G.P.; Yapryntsev, A.D.; Ustinovich, K.B.; Chennevière, A.; Ivanov, V.K. 1D Ceric Hydrogen Phosphate Aerogels: Noncarbonaceous Ultraflyweight Monolithic Aerogels. ACS Omega. 2020, 5, 17592-17600, https://doi.org/10.1021/acsomega.0c02061.

42. Hammouda, B. A New Guinier-Porod Model. J. Appl. Crystallogr. 2010, 43, 716-719, https://doi.org/10.1107/S0021889810015773.

43. Guinier, A.; Fournet, G. Small-Angle Scattering of X-Rays. John Wiley \& Sons, Inc.: New York, 1955.

44. Bale, H. D.; Schmidt, P. W. Small-Angle X-Ray-Scattering Investigation of Submicroscopic Porosity with Fractal Properties. Phys. Rev. Lett. 1984, 38, 596-599, https://doi.org/10.1103/PhysRevLett.53.596.

45. Guinier, A.; Frournet, G.; Walker, C. B.; Yudowitch. K. L. Small-Angle Scattering of X-rays. New York: Wiley, 1955; 17.

46. Schmidt, P.W. Some Fundamental Concepts and Techniques Useful in Small-Angle Scattering Studies of Disordered Solids. In Modern Aspects of Small-Angle Scattering Brumberger, H. Ed. Dordrecht: Kluwer Academic Publishers, 1995; 1-56. 